\title{
Outcome of Buck's fascia repair with wingless glanuloplasty in distal penile hypospadias
}

\author{
Mir Fahiem-Ul-Hassan*, Vinay Jadhav, Narendrababu Munianjanappa, Murali Saroja and \\ Ramesh Santhanakrishnan
}

\begin{abstract}
Background: Hypospadias surgery is technically demanding and is often encountered with complications like fistula and glanular dehiscence. To prevent these complications we have instituted Buck's fascia repair (BFR) with wingless glanuloplasty (WLP) in the cases of distal penile hypospadias (DPH) deemed to be suitable for TIP repair. The aim of this prospective study was to assess the outcome of Buck's fascia repair (BFR) with minimal wingless glanuloplasty (WGP).
\end{abstract}

Methods: This prospective study included 50 patients with coronal, subcoronal and midpenile hypospadias who received a tubularization of incised plate (TIP) repair. The exclusion criteria were glanular hypospadias, Thiersch Duplay repair, proximal penile hypospadias, previous penile surgeries, uncorrectable chordee, glans size $<14 \mathrm{~mm}$, flat glanular groove and preoperative testosterone therapy.

Results: Over a period of 3 years, 50 patients with mean age of $3.5 \pm 0.8$ years were recruited for the study. Meatal position was coronal, subcoronal and midpenile in 6, 24 and 20 patients, respectively. Fistula occurred in one patient (2\%) and meatal stenosis in one. Straining on micturition was noted in two patients that needed dilatation in postoperative period. None of the patients had glanular dehiscence. Surgeon acceptability of the procedure was good. Cosmetic results were also fair.

Conclusion: Buck's fascia repair with Wingless glanuloplasty is a good repair for the distal penile hypospadias. It is effective and is associated with low fistula rates and glanular dehiscence. It is technically simple procedure involving minimal dissection. However, caution should be observed in midpenile hypospadias to avoid tight repair in subcoronal region.

Keywords: Buck's fascia repair, Wingless glanuloplasty, Tubularization of incised plate, Fistula, Glanular dehiscence

\section{Background}

Hypospadias is one of a common surgical condition in children with distal penile hypospadias forming the bulk of the cases [1]. Over years a myriad of procedures were developed and applied for the repair but till now there is no single procedure which would address all the aspects

\footnotetext{
*Correspondence: drfaheemandrabi@gmail.com

Department of Pediatric Surgery and Pediatric Urology, Indira Gandhi Institute of Child Health, Jayanagar, Bangalore 560029, India
}

for the successful outcome [2]. In 1994, tubularization of incised plate (TIP) was described which later became the most commonly performed technique for distal penile hypospadias (DPH) repair [3]. TIP aptly addresses the issues of narrow urethral plate but still has a complication rates just over $10 \%$, of which fistula is most common [4]. To obviate the incidence of fistula occurrence secondary layers like de-epithelised skin, spongiosum, dartos flap and tunica vaginalis flap have been used to cover the neourethra with variable results. However, the quest for most 
ideal intermediate layer is still on [5, 6]. Recently Buck's fascia as an intermediate layer has shown very promising results due to it being a tough tissue layer with high tensile strength [7]. Apart from fistula formation, hypospadias repair may be associated with glanular dehiscence which is a common and significant complication given the fact that such patients typically need a redo procedure $[8,9]$. Owing to this, we instituted Buck's fascia repair with wingless glanuloplasty for the patients with midpenile and distal penile hypospadias and assessed the outcome of this novel technique with regards to prevention of fistula, cosmetic results at our high volume tertiary care center.

\section{Methods}

This prospective study was conducted from July 2017 to July 2020 and included 50 patients of distal penile hypospadias. Patients with coronal, subcoronal and midpenile hypospadias who were deemed to be amenable for TIP repair were included in the study. These were the patients who after receiving a dorsal incision in the urethral plate attained adequate urethral plate width for tubularization over an eight French catheter. The exclusion criteria were glanular hypospadias, Thiersch Duplay repair, proximal penile hypospadias, previous penile surgeries and residual chordee after degloving and plication. For wingless glanuloplasty, a healthy glans with size of $\geq 14 \mathrm{~mm}$ formed the inclusion criteria whereas glanular size $<14 \mathrm{~mm}$, flat glanular groove and preoperative testosterone therapy formed the exclusion criteria.

\section{Procedure}

Patients were taken for repair under general anesthesia and caudal analgesia. After scrubbing, glanular stay suture was applied followed by catheter insertion and tourniquet placement. Urethral plate width and glanular size were measured. All the repairs were done under loupes with $3.5 \times$ magnification. After a routine peri-urethral incision, peri-urethral triangle (PUT) was marked with the apex of the triangle being formed by the point representing the inferior extent of the proposed meatus and its sides being formed by the periurethral incision and a line running along the edge of the glans upto 2-4 mm (Fig. 1). The skin of this triangle was excised to allow the future glanuloplasty without raising the formal glanular wings (Fig. 2). Penis was degloved, Snodgrass type slit incision was made in urethral plate and urethroplasty done with size 6 polydioxanone sutures (PDS) starting from the proximal end (Fig. 3). Continuous subcuticular suturing was performed till the neomeatus where the suture was tied and cut. Buck's fascia repair commenced from just proximal to the urethroplasty (Fig. 4) and was carried on towards the tip in a

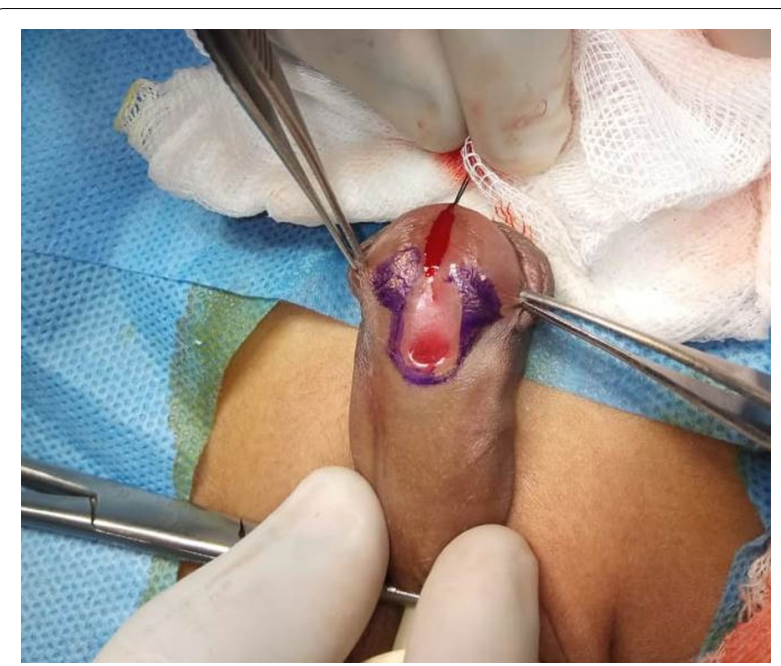

Fig. 1 Periurethral incision and periurethral triangles are marked

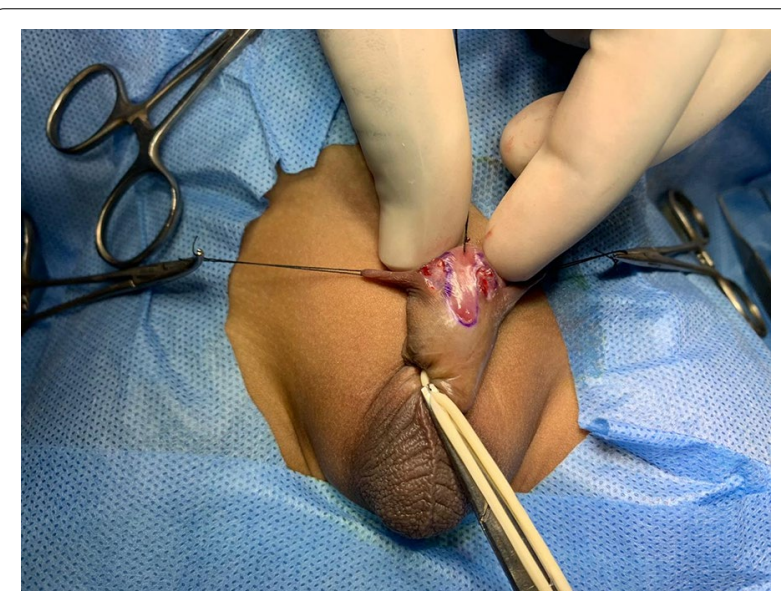

Fig. 2 Skin of the peri-urethral triangles excised to allow future glanuloplasty

continuous fashion incorporating the inner raw area of glans. This suture was returned again in a continuous manner on the external surface of glans and tied at corona (Fig. 5). Circumcision was performed and dressing applied which was removed on 4th postoperative day (Fig. 6). Catheter was removed on 8-10 postoperative day. Patients were followed up on monthly basis till six months after surgery. Data were collected and analyzed by SPSS 2015 (Version 23.0. Armonk, NY: IBM Corp.)

\section{Results}

Over a period of 3 years 50 patients were recruited for this prospective study. The mean age of the patients was $3.5 \pm 0.8$ years. Meatal position was coronal, subcoronal and midpenile in 6,24 and 20 patients, respectively 


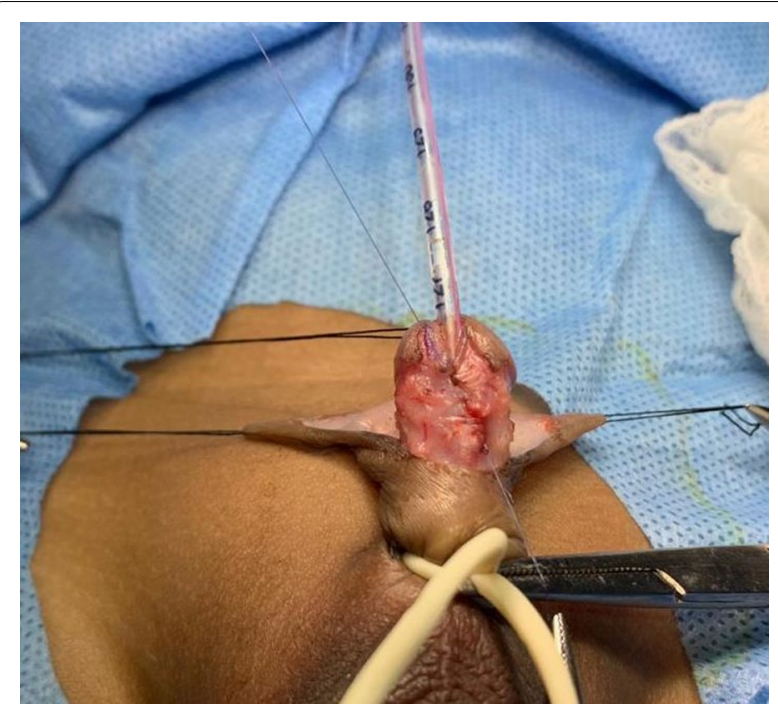

Fig. 3 Urethroplasty with 6-0 PDS being performed from the proximal to distal end

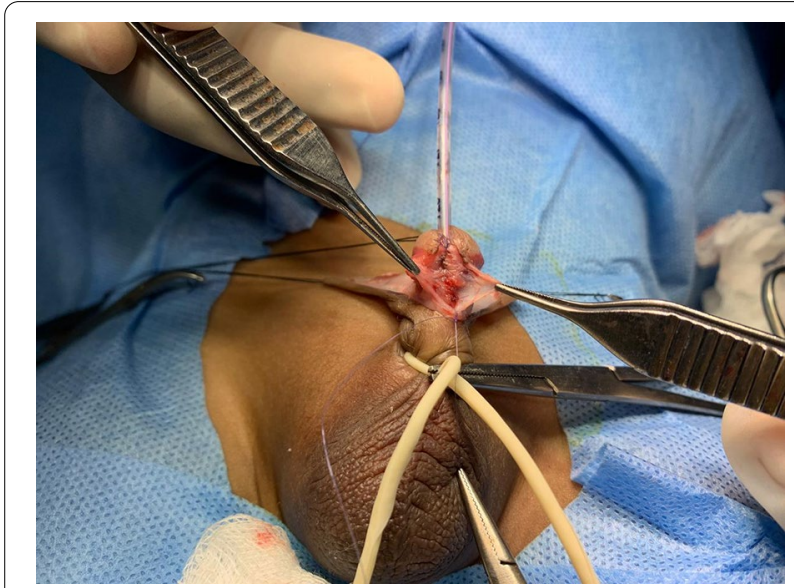

Fig. 4 Buck's Fascia being sutured over the urethroplasty as an interposition layer. Note that Buck's Fascia is a thick and well defined layer which does not need much dissection

(Table 1). Mean width of urethral plate was $8.4 \mathrm{~mm}$ (range 7.8-9.7 mm) and mean glanular size was $14.4 \mathrm{~mm}$ (range 14.0-14.9 mm) measured by vernier calipers. Ten patients had associated chordee which was corrected in 8 patients with degloving only, while as two patients required tunica albugenia plication. The mean time from the commencement of the incision to completion of dressing was $53 \pm 12 \mathrm{~min}$. Following the repair, fistula occurred in one patient $(2 \%)$ who also had meatal stenosis (Table 2) diagnosed clinically by pinpoint meatus. None of the patients had glanular dehiscence. We also observed subcoronal tightening in two patients who had straining \& difficulty in initiation of micturition in

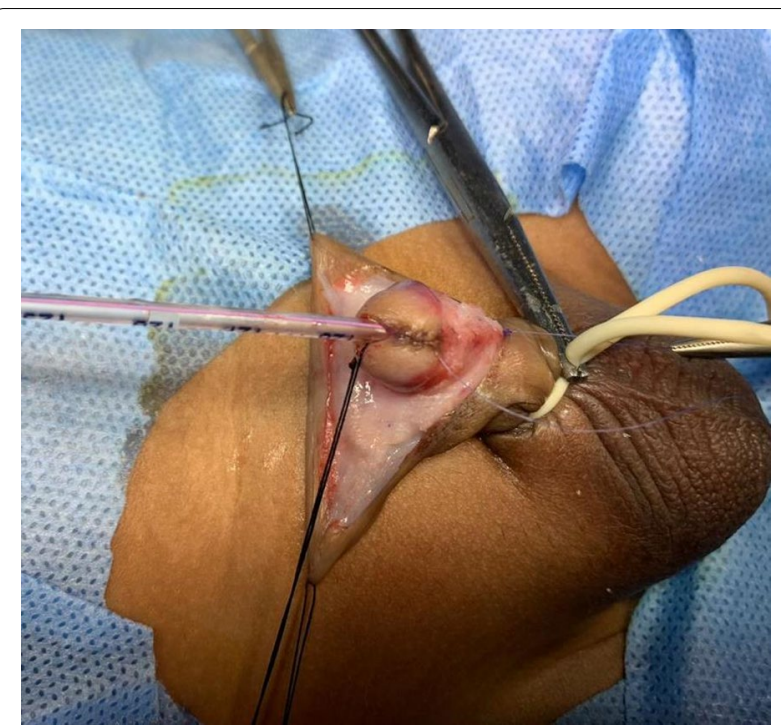

Fig. 5 Glanuloplasty is done in two layers. The suturing of the Buck's Fascia continues into the inner raw surface of glans which is then brought outside and glans closed externally in a continuous manner. The suture is tied at coronary skin collar

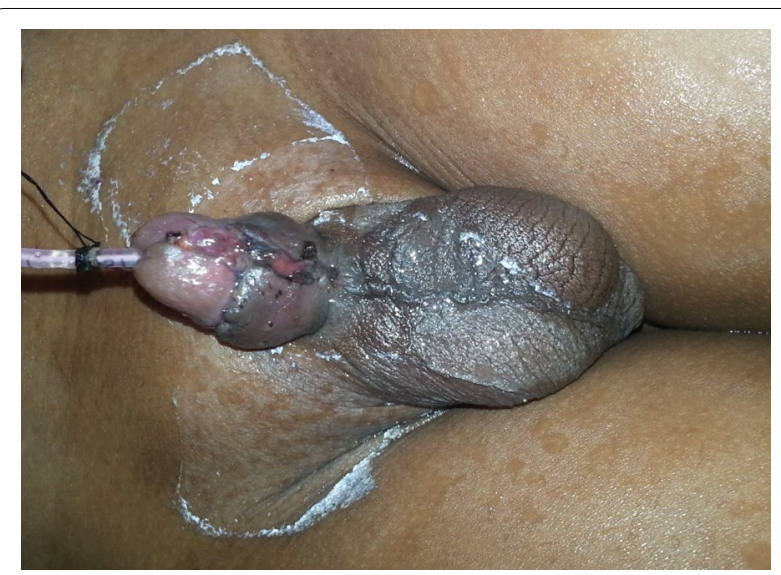

Fig. 6 Appearance at the time of dressing on 4th postoperative day

Table 1 Position of meatus

\begin{tabular}{lcc}
\hline Position of meatus & No. of patients & $\%$ \\
\hline Coronal & 6 & 12 \\
Subcoronal & 24 & 48 \\
Mid penile & 20 & 40 \\
\hline
\end{tabular}

postoperative period. Both of these patients had midpenile hypospadias. Overall, in $4 \%$ patients ( 2 out of 50 ) but, if viewed separately, this complication was seen in $10 \%$ patients of midpenile hypospadias ( 2 out of 20). These two patients required urethral dilatation for a period of 
Table 2 Complications

\begin{tabular}{lll}
\hline Complications & No. of patients & $\%$ \\
\hline Urethrocutaneous fistula & 1 & 2 \\
Meatal stenosis & 1 & 2 \\
Glanular dehiscensce & 0 & 0 \\
Subcoronal tightening & 2 & 4 \\
Difficulty in initiation of micturition & 2 & 4 \\
\hline
\end{tabular}

4-5 weeks. Though the straining improved, the uroflowmetry showed subnormal maximum flow rates (Table 3). Urethroscopy did not show any stricture or meatal stenosis. The cosmetic results were very good with regards to the position and shape of meatus \& conical appearance of glans (Fig. 7).

We also trained ten pediatric urology residents in BFR with WLG. They were made to assist at least three BFR with WLG urethroplasties. They also assisted similar number of conventional TIP urethroplasties with dartos flap coverage in our sister unit. At the end, their preferences regarding the choice of procedure were sought through a small questionnaire. Nine out of ten favored BFR with WLG citing it to be technically simple.

\section{Discussion}

The surgical techniques of the hypospadias repair have evolved and improved over years but nevertheless, it still remains a challenge for many hypospadiologists on account of complications faced following the repair which may include wound infection, wound dehiscence, flap necrosis, chordee, torsion and fistula formation [10, 11]. Among all complications fistula is most common and demanding complication with an incidence rate of 0-23\% [8]. Multiple factors like local infection, ischemia, meatal narrowing, long suture line, suturing material and surgical technique and expertise have been implicated in the formation of fistula [8]. Several strategies have been adopted to prevent the fistula formation which includes use of magnification, use of fine instruments and fine sutures and reinforcement of urethroplasty with an additional tissue layers in the form of de-epithelised skin, spongiosum, dartos flap and tunica vaginalis flap [12]. Dartos and tunica vaginalis flaps are more frequently used as the interposition layers to prevent fistula

Table 3 Characteristics of patients of subcoronal tightening

\begin{tabular}{lllll}
\hline & Position & Qmax ml/s & Dilatation & Result \\
\hline Patient 1 & Midpenile & 6.9 & 4 weeks & Improved \\
Patient 2 & Midpenile & 6.4 & 5 weeks & Improved \\
\hline
\end{tabular}

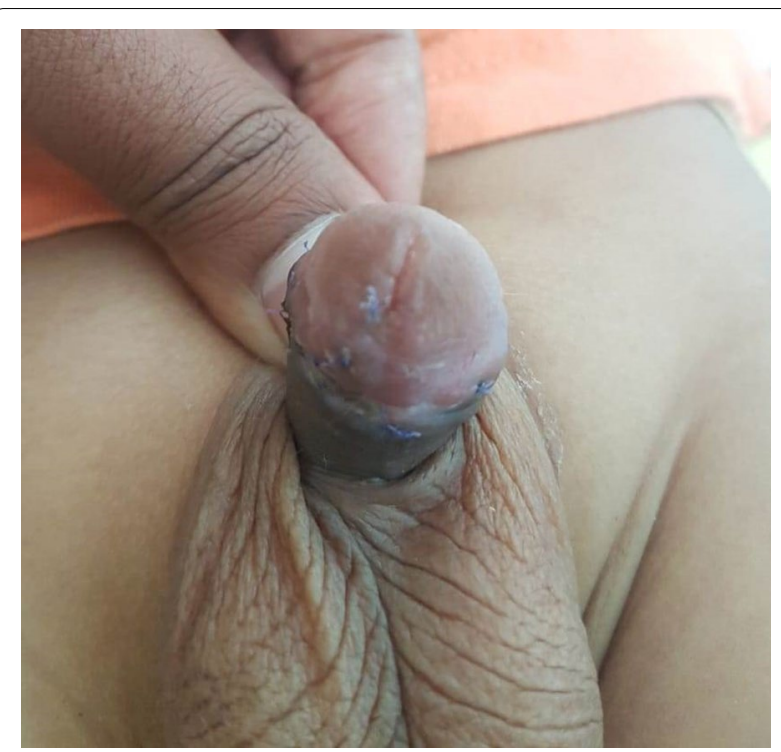

Fig. 7 Final results. Note the conical glans and normal appearance of meatus

formation. However, dartos flap has been associated with torsion and ischemia of the penile skin while as tunica vaginalis may lead to chordee besides risking the injury to testis and its vascularity $[13,14]$. This makes Buck's fascia particularly valuable as an interposition layer to reinforce the urethroplasty as it is devoid of such complications. It is easily available, tough tissue layer, which does not need extensive dissection or tailoring unlike tunica vaginalis and dartos flaps. Moreover, we found it to be highly effective in reducing the fistula rates which were $2 \%$ in our study thus similar to the findings by Baba et al. [7]. Holland and Smith [15] attributed fistula and other complications to the adverse configurations of urethral plate. They observed fistula in $55 \%$ of their patients with narrow urethral plate. However, this finding was contrary to the study by Nguyen Nguyen and Snodgrass [16] who reported fistula in only one patient (3.3\%) of narrow urethral plate thereby implicating that urethral plate configuration is not the sole factor determining the complications. Other technical factors like inversion of suture line and neourethral coverage play a significant role in minimizing the fistula rates [16]. Our experience of Buck's fascia as a neourethral coverage, with a fistula rate of $2 \%$, is in concordance with the later study though the urethral plate width was smaller in our patients $(7.8 \mathrm{~mm})$. Only one patient $(2 \%)$ in our study had meatal stenosis. The same patient also had a fistula. The incidence of meatal stenosis is thus comparable with the standard TIP repairs [7, 17].

It will be worthwhile to mention here that we noticed sub-coronal tightening (Fig. 8) in two of our patients. 


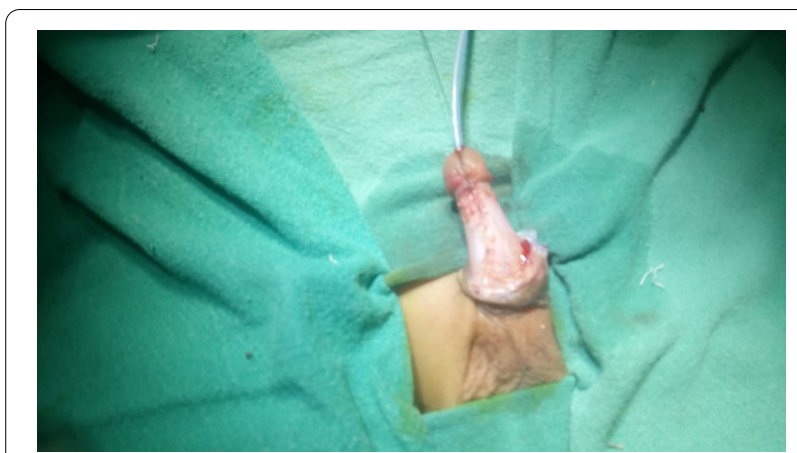

Fig. 8 Subcoronal tightening as witnessed in two patients

As the urethroplasty was done on eight French catheter, it was deemed by the authors that the tightening might not manifest in symptoms. However, both of them reported difficulty in initiation of micturition. This complication was seen primarily in midpenile hypospadias, thus requiring urethral dilatations over a period of 4-5 weeks following which the straining improved. Though clinically asymptomatic after dialtations, these patients continued to have subnormal maximum flow (Qmax) on uroflowmetry at three months postoperatively (Table 3 ). However, obstructive flow rates are common after TIP (Snodgrass) repair. Piplani et al. have observed obstructive pattern on uroflowmetry in $69 \%$ of their patients of urethroplasty. The urinary flow rates usually improve with time [18]. Continued improvement at 7 years after surgery has been observed on further follow up with Qmax reaching $19 \mathrm{ml} / \mathrm{min}$ thereby implying improved tissue elasticity and pliability with time [19]. As mentioned earlier, both of these patients had mid-penile hypospadias. The possible explanation being that in midpenile hypospadias the spongiosum and the Buck's fascia divide early and are divergent distally towards the corona. The re-approximation of this divergent Buck's fascia may occasionally cause mild tightening in the coronal and sub-coronal region, which may lead to difficulty in initiating the stream postoperatively. These symptoms may be pronounced in immediate postoperative period due to the superimposed edema of the tissues. As the edema settles and the dilatation is undertaken, the straining is gradually relieved. To predict this complication, we propose that the first suture of buck's fascia closure should be taken distally in the coronal/subcoronal region to look for the tightening. Rest of the closure will be carried out as described in the methods. A persistent tightening in the region may necessitate switching over to other options of neo-urethral coverage. The authors are now making lateral incisions in Buck's fascia to allow its loose approximation in the midline, a modification that is under investigation.

Another principle domain of this study is the institution of wingless glanuloplasty instead of conventional glanuloplasty. Conventional glanuloplasty involves dissection of glans wings laterally to three and nine o' clock positions. A correct plane between the glans and the corpora is crucial to achieve sufficiently thick glans wings for approximation. At times over-enthusiastic dissection leads to excessive bleeding and holes in the urethral plate which may results in suboptimal outcomes [4]. Even with the extra caution and care observed while mobilizing the glans wings, glanular dehiscence does occur. Snodgrass et al. have reported glans dehiscence rates ranging from 4 to $15 \%$ of the patients, with the chances of dehiscence being more with proximal hypospadias and small glans size [20]. In our series none of the patients had glanular dehiscence perhaps because minimal wingless glanuloplasty does not interfere with the vascular planes of the glans and also partly because we restricted WGP to glans size of $>14 \mathrm{~mm}$. Baba et al. have also produced similar results even though $10 \%$ of their patients included proximal hypospadias [7].

The most outstanding feature of the BFR with WLG is that it is does not need extensive dissection. Being simple and effective [21] it may emerge as a valuable procedure for teaching and learning purposes especially for the pediatric urology residents and fellows. Cosmetic results with regards to glans shape and meatal location in all our patients were also fairly good barring the one patient with fistula.

\section{Conclusion}

Buck's fascia repair with Wingless glanuloplasty is a good repair for the distal penile hypospadias. It is effective in reducing the fistula and glanular dehiscence rates. It is technically simple procedure and involves minimal tissue dissection. However, caution should be observed in midpenile hypospadias to avoid tight repair in subcoronal region.

\section{Abbreviations}

BFR: Buck's fascia repair; WLG: Wingless glanuloplasty; TIP: Tubularisation of incised plate; DPH: Distal penile hypospadias; PUT: Peri-urethral triangle.

\section{Acknowledgements}

Dr. Aejaz A. Baba, Professor, Pediatric and Neonatal Surgery, Sheri Kashmir Institute of Medical Sciences, Soura Srinagar Kashmir.

\section{Authors' contributions}

MFH conceived and designed the study, prepared the manuscript, VJ \& NM performed the procedures. MS \& RS, analyzed and interpreted the data. All authors read and approved the manuscript. 


\section{Funding}

No funding was required for the study.

\section{Availability of data and materials}

The data used to support the findings of this study are available from the corresponding author upon request.

\section{Declarations}

Ethics approval and consent to participate

Ethical approval was obtained from Indira Gandhi Institute of Child Health Ethical Committee. Reference no. currently not available. Written informed consent was taken from legal guardians of the patients.

\section{Consent for publication}

Consent for publication was received from the guardians of the participants of the study.

\section{Competing interests}

The authors declare that they have no known competing financial interests or personal relationships that could have appeared to influence the work reported in this paper.

Received: 19 February 2021 Accepted: 10 May 2021

Published online: 22 May 2021

\section{References}

1. Keays MA, Dave S (2017) Current hypospadias management: diagnosis, surgical management, and long-term patient-centred outcomes. Can Urol Assoc J 11(1-2 suppl 1):S48. https://doi.org/10.5489/cuaj.4386

2. Springer A (2014) Assessment of outcome in hypospadias surgery-a review. Front Pediatr 20(2):2. https://doi.org/10.3389/fped.2014.00002

3. Snodgrass W, Bush N (2016) Primary hypospadias repair techniques: a review of the evidence. Urol Ann 8(4):403. https://doi.org/10.4103/09747796.192097

4. Docimo SG, Canning D, Khoury A, Salle JL (2018) The Kelalis--King--Belman textbook of clinical pediatric urology. CRC Press

5. Saiad MO (2018) The modified multilayer coverage of urethroplasty for distal hypospadias. J Indian Assoc Pediatr Surg 23(3):140. https://doi.org/ 10.4103/jiaps.JIAPS_164_17

6. Basavaraju M, Balaji DK (2017) Choosing an ideal vascular cover for Snodgrass repair. Urol Ann 9(4):348. https://doi.org/10.4103/UA.UA_90_ 17

7. Baba AA, Wani SA, Bhat NA, Mufti GN, Lone TN, Nazir S (2017) Buck's fascia repair with glanuloplasty in hypospadias surgery: a simple approach with excellent outcome. J Pediatr Urol 13(6):633. https://doi.org/10.1016/j. jpurol.2017.06.015
8. Bhat A, Mandal AK (2008) Acute postoperative complications of hypospadias repair. Indian J Urol 24(2):241. https://doi.org/10.4103/0970-1591. 40622

9. Snodgrass W, Cost N, Nakonezny PA, Bush N (2011) Analysis of risk factors for glans dehiscence after tubularized incised plate hypospadias repair. J Urol 185(5):1845-1851. https://doi.org/10.1016/j.juro.2010.12.070

10. Hashish A, Al-Balushi A, Haridi K, Al-Busaidi S (2017) Hypospadias Repair and Its Complications at the Plastic Surgery Department, Khoula Hospital. Modern Plastic Surg 7(02):13. https://doi.org/10.4236/mps.2017.72002

11. Manzoni G, Bracka A, Palminteri E, Marrocco G (2004) Hypospadias surgery: when, what and by whom? BJU Int 94(8):1188-1195. https://doi. org/10.1046/j.1464-410x.2004.05128.x

12. Hadidi A (ed) (2013) Hypospadias surgery: an illustrated guide. Springer, New York

13. Hamid R, Baba AA, Shera A, Ahmad S (2015) Tunica vaginalis flap following 'Tubularised Incised Plate'urethroplasty to prevent urethrocutaneous fistulaa. Indian J Plastic Surg 48(02):187-191. https://doi.org/10.4103/ 0970-0358.163059

14. Dhua AK, Aggarwal SK, Sinha S, Ratan SK (2012) Soft tissue covers in hypospadias surgery: is tunica vaginalis better than dartos flap? J Indian Assoc Pediatr Surg 17(1):16. https://doi.org/10.4103/0971-9261.91080

15. Holland AJ, Smith GH (2000) Effect of the depth and width of the urethral plate on tubularized incised plate urethroplasty. J Urol 164(2):489-491. https://doi.org/10.1016/S0022-5347(05)67408-3

16. Nguyen MT, Snodgrass WT (2004) Effect of urethral plate characteristics on tubularized incised plate urethroplasty. J Urol 171(3):1260-1262. https://doi.org/10.1097/01.ju.0000110426.32005.91

17. Snodgrass W, Koyle M, Manzoni G, Hurwitz R, Caldamone A, Ehrlich R (1996) Tubularized incised plate hypospadias repair: results of a multicenter experience. J Urol 156(2S):839-841. https://doi.org/10.1016/ S0022-5347(01)65835-X

18. Piplani R, Aggarwal SK, Ratan SK (2018) Role of uroflowmetry before and after hypospadias repair. Urol Ann 10(1):52. https://doi.org/10.4103/UA. UA_78_17

19. Andersson M, Doroszkiewicz M, Arfwidsson C, Abrahamsson K, Holmdahl G (2011) Hypospadias repair with tubularized incised plate: does the obstructive flow pattern resolve spontaneously? J Pediatr Urol 7(4):441445. https://doi.org/10.1016/j.jpurol.2010.05.006

20. Snodgrass W, Bush N (2014) Recent advances in understanding/management of hypospadias. F1000prime Reports. https://doi.org/10.12703/ P6-101

21. Xu D (2020) Application of Buck's fascia to restore the complete wrapping of the neourethra with corpus spongiosum in tubularized incised plate urethroplasty in hypospadias. J Pediatr Urol 1(16):S56. https://doi. org/10.1016/j.jpurol.2020.05.128

\section{Publisher's Note}

Springer Nature remains neutral with regard to jurisdictional claims in published maps and institutional affiliations.

\section{Submit your manuscript to a SpringerOpen ${ }^{\circ}$ journal and benefit from:}

- Convenient online submission

- Rigorous peer review

- Open access: articles freely available online

- High visibility within the field

- Retaining the copyright to your article

Submit your next manuscript at $\boldsymbol{\nabla}$ springeropen.com 